\title{
ATIVISMO E ESTRATÉGIAS DE VISIBILIDADE DE BLOGS FEMINISTAS NO TUMBLR
}

\author{
Quesia Silva do Carmo
} Edvaldo Souza Couto ${ }^{(*)}$

\section{INTRODUÇÃO}

O nosso tempo é dominado pelas Redes Sociais na Internet (RSI) em que publicar e falar de si são palavras e ações de ordem. A todo momento nos deparamos com as mais diversas narrativas do eu em um universo de redes, imagens e textos em constante movimento e expansão. Precisamos ser vistos para existirmos. Precisamos publicar, interagir e expor nossos gostos e subjetividades na internet. A visibilidade é uma constante nas redes e é também um valor em si. Para alcançá-la, mais do que publicizar conteúdo são necessárias estratégias que tornem as informações visíveis, rastreáveis e interpretáveis (SANTANA; COUTO, 2017). Essas estratégias para a visibilidade de si também promovem valores e comportamentos específicos a respeito do ativismo feminista.

Além do mais, essa constante exposição de si não consiste apenas de confissões sobre os mais íntimos desejos e sentimentos, mas também do que se acredita, posições e causas sociais e políticas. Ao se expor uma causa na internet, pretende-se torná-la visível. Portanto, as redes sociais tem se tornado com o passar dos anos espaços de debates e atos políticos efervescentes, tanto individuais quanto coletivos. E um dos movimentos que mais cresce nos últimos tempos é o feminismo, graças, principalmente, ao grande fluxo de narrativas feministas na rede.

Tendo em vista esse contexto, o objetivo do artigo é identificar, descrever e analisar o ativismo e as estratégias de visibilidade utilizadas por um grupo de pessoas autodeclaradas feministas em seus blogs na rede social Tumblr. Para atingir esse objetivo o estudo considerou

\footnotetext{
${ }^{(*)}$ Quesia S. Carmo. Mestre em Educação pela Universidade Federal da Bahia (UFBA). Orcid: <http://orcid.org/00000002-1491-2161>.

Edvaldo S. Couto. Doutor em Educação pela UNICAMP. Bolsista de Produtividade em Pesquisa pelo CNPq. Professor no Departamento de Educação II (FACED/UFBA). Co-coordenadores do Grupo de Pesquisa Educação e Comunicação e Tecnlogias (GEC) e lider do Grupo de Pesquisa Educação, redes sociotécnicas e culturas digitais (EDUTEC). Orcid: 〈http://orcid.org/0000-0002-2648-9399>
} 
como o feminismo tem se espalhado pela rede e as estratégias mais comuns para lhe dar visibilidade.

$\mathrm{O}$ artigo foca nas estratégias de visibilidade utilizadas por essas feministas nesses blogs para promover suas páginas pessoais e colaborativas na internet, onde trocam informações sobre seus temas de interesse considerando que o Tumblr é uma rede social jovem e com constante circulação de conteúdo feminista. Analisar as estratégias de visibilidade é importante para ressaltar o ativismo feminista e os tipos de discursos produzidos, bem como a circulação dessas ações entre jovens mulheres quanto ao feminismo.

\section{REDES SOCIAIS E NARRATIVAS DE SI}

A cultura criada e moldada no ciberespaço é conhecida por cibercultura, podendo ser resumida como "o conjunto de técnicas (materiais e intelectuais), de práticas, de atitudes, de modos de pensamento e de valores que se desenvolvem juntamente com o crescimento do ciberespaço" (LÉVY, 1999, p. 17). Apesar de surgir no ciberespaço, a cibercultura pode intervir no mundo offline e vice-versa, sendo a linha que os separa (ou separava) cada vez mais tênue. Essa característica a cada dia mais perceptível na cibercultura é também conhecida como cibridismo ${ }^{1}$.

No ciberespaço nos deparamos com redes sociais onde se dão grande parte das interações entre os internautas. "Uma rede social é definida como um conjunto de dois elementos: atores (pessoas, instituições ou grupos; os nós da rede) e suas conexões (interações ou laços sociais)" (RECUERO, 2009, p. 24). O que caracteriza a dinâmica das redes sociais no ciberespaço é que neste trabalha-se "com representações dos atores sociais, ou com construções identitárias [...]. Um ator, assim, pode ser representado por um weblog, por um fotolog, por um twitter ou mesmo por um perfil no Orkut" (RECUERO, 2009, p. 25) e em outras redes sociais digitais mais recentes como Facebook, Instagram, Twitter e Tumblr.

Da mesma forma que no cotidiano offline utilizamos de diversas estratégias para nos comunicar e socializar, na internet a possibilidade de criação e uso de estratégias é ainda maior, sendo estas alimentadas quase sempre por narrativas de si que moldam o eu no ciberespaço,

\footnotetext{
${ }^{1}$ Mais informações sobre o que é cibridismo e suas características podem ser vistos na palestra "Cibridismo: o fim do mundo offline" de Martha Gabriel. Disponível em: 〈http://www.youtube.com/watch?v=apyFQEUUTPA〉. Acesso em 23 mai. 2019.
} 
viabilizando a criação de subjetividade que irá interagir e se mostrar aos demais. Nas RSI cada ator possui um perfil individual que o representará virtualmente e onde acrescentará o conteúdo que bem entender, seja referente à sua vida privada ou não.

As narrativas pessoais não devem ser vistas apenas sob a ótica de um possível narcisismo acentuado dessa época de conexões velozes. Elas oferecem, igualmente, um frescor na breve capacidade de criar e se expressar, nos modos pelos quais se tornou possível, em rede, construir identidades e subjetividades borbulhantes (COUTO, 2015, p. 180).

Nesse contexto proliferam as narrativas de si. Tais narrativas se referem a questões pessoais, onde pessoas relatam suas experiências e gostos. Mas são, também, explanações que exibem posicionamentos sociais, políticos, educacionais. Então, as narrativas de si falam do sujeito, mas também das suas percepções de mundo, de tudo aquilo que considera importante dos acontecimentos e notícias que circulam no ciberespaço. Em outras palavras, as narrativas de si fazem parte de um conjunto de declarações que cada um publiciza para defender e valorizar seus interesses, suas bandeiras políticas, seu ativismo na cibercultura (SILVEIRA, BRAGA; PENTEADO, 2014).

\section{O Tumblr}

Dentro do universo de redes sociais disponíveis a apenas um clique existe o Tumblr, criado em 2007, por David Karp, e hoje composto por 333 milhões de blogs e disponível em 17 idiomas ${ }^{2}$. Por ser um microblog, o Tumblr é um híbrido de blog e rede social. Os blogs tradicionais, como o Blogspot, possuem conteúdos de alta qualidade, porém pouca interação entre seus membros. Já redes sociais, como o Facebook e o Instagram, possuem grande índice de interação, mas conteúdos de menor qualidade em comparação à blogosfera. Os microblogs estão na divisa entre os blogs tradicionais e as redes sociais de internet, tendo tanto qualidade de conteúdo quanto interações sociais em nível intermediário (CHANG et al., 2014).

Enquanto rede social, o Tumblr possui uma dinâmica de interação social semelhante a do Twitter, pois:

Enquanto nas outras redes sociais como Facebook, Orkut, etc., o foco da interação social está nos contatos pessoais entre usuários, no Twitter o foco encontra-se na qualidade e no tipo de conteúdo veiculado por um usuário específico (SANTAELLA e LEMOS, 2010, p. 67)

\footnotetext{
${ }^{2}$ Disponível em: 〈https://www.tumblr.com/about>. Acesso em: 20 abr. 2019.
} 
Não é necessário haver uma associação mútua entre membros para que tenham acesso um ao blog do outro. Pode-se seguir quem quiser sem a necessidade de autorização prévia e vice-versa. Os laços são, portanto, constituídos a partir da identificação com o que se é publicado e não necessariamente a partir de relações anteriores ou offline com o dono ou dona do blog. Segundo Malini e Antoun (2013, p. 196), “a invenção do Tumblr e Twitter significou um novo passo na cultura blogueira", pois antes o público dos blogs era misterioso e com a hibridização dessas plataformas de blog com as redes sociais, hoje em dia, a interação dos blogs com seus seguidores é muito mais próxima e dinâmica, proporcionando ações como republicações, curtidas e menções diretas ao dono do blog.

Qualquer pessoa pode fazer parte do Tumblr, uma vez que só é solicitado um e-mail válido, o nome de usuário de sua preferência (e que ainda não tenha sido utilizado por ninguém) e uma senha. Não há nenhum tipo de burocracia para saber a real identidade de seus membros (como por vezes ocorre com o Facebook), e é comum o total ocultamento de identidade. São raros os perfis que fazem uso de fotos pessoais ou que revelam sua localização geográfica, o que torna o Tumblr um local propício para confissões e publicação de conteúdo sem amarras. O que mais importa é publicar seus gostos pessoais, suas crenças, ideias e até mesmo os mais íntimos fetiches.

Vale à pena também ressaltar que toda vez que se faz login na página do Tumblr uma nova imagem que foi publicada no site aparece como background com os devidos créditos ao blog que a publicou, demonstrando que há uma valorização do conteúdo compartilhado pelos seus membros. Em relação às postagens, o Tumblr possui uma plataforma bastante simples e interativa de fácil uso que permite o compartilhamento de diversas mídias sendo estas: texto, foto, citação, link, chat, áudio ou vídeo, visíveis na imagem a seguir:

\section{Figura 1.Tipos de posts do Tumblr}

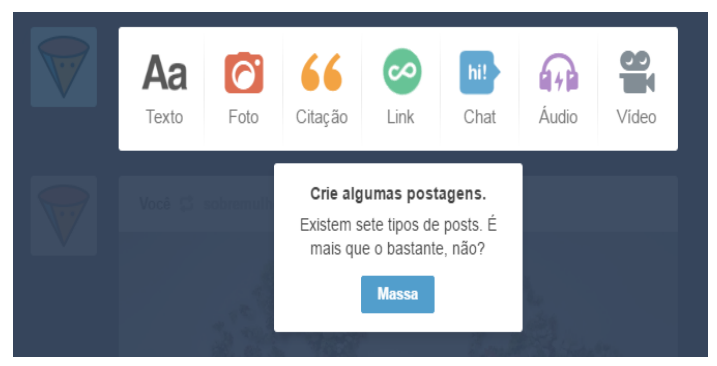

Fonte: Figura elaborada pelos autores 
Essa variedade de utilidades e a sua própria estrutura facilitam bastante a visualização e compartilhamento de informação e, em meio ao "mar de confissões íntimas", o Tumblr se tornou também, com o tempo, uma rede com grande circulação de postagens de cunho social e ativista. Segundo matéria escrita por Valeriya Safronova, para o The New York Times, em dezembro de 2014:

There are more than 215 million blogs on Tumblr and, according to comScore, an analytics company, 50 percent of Tumblr users are from 15 to 34 years old. The company's internal surveys show that 64 percent of users say that they care about social causes and look into them on Tumblr. These numbers suggest that millennials, who have long been pigeonholed as an apathetic bunch, have a strong interest in social issues - it's just hidden from the eyes of their elders (SAFRONOVA, 2014). ${ }^{3}$

Se tornam nítidas as potencialidades educacionais da rede à medida que muitos se informam sobre determinados temas e passam a se engajar fortemente em suas causas e em educar outras pessoas. O que pode ser percebido pela grande quantidade de compartilhamento de material educacional sobre questões sociais, mas também na criação de novos conteúdos.

O Tumblr, nessa pesquisa, é analisado como um exemplo de rede social em que esse tipo de interação e narrativas engajadas para com o social ocorre auxiliando no entendimento de um quadro mais geral dos movimentos sociais no contexto da sociedade em rede (CASTELLS, 2005), em especial, o feminismo.

\section{Percurso metodológico}

Para desenvolver a pesquisa usamos o método qualitativo, de cunho descritivo e analítico, e a técnica utilizada para a coleta de dados foi a observação encoberta: "[...] nesse tipo de observação, o pesquisador apenas observa o seu campo de estudo, sem que os sujeitos observados saibam que estão sendo estudados" (LASTA e BARICHELLO, 2013, p. 253). Inicialmente, foi feito um levantamento bibliográfico para a fundamentação teórica e em seguida uma análise qualitativa das publicações, fazendo com que as categorias "formato", "fonte" e "tipo de publicação" fossem construídas a partir dos dados obtidos. Tal escolha surge a partir do olhar das redes sociais enquanto artefatos culturais, onde o online e o offline se misturam e ambos estão

\footnotetext{
${ }^{3}$ Existem mais de 215 milhões de blogs no Tumblr e, de acordo com a comScore, uma empresa de análise, 50\% dos usuários do Tumblr têm entre 15 e 34 anos. As pesquisas internas da empresa mostram que $64 \%$ dos usuários dizem que se preocupam com causas sociais e pesquisam sobre eles no Tumblr. Esses números sugerem que os millennials, que há muito tempo têm sido rotulados como um grupo apático, têm um forte interesse em questões sociais - é apenas escondido dos olhos dos mais velhos. (SAFRONOVA, 2014. Tradução nossa).
} 
incorporados à vida cotidiana (FRAGOSO et al., 2011). Assim, uma pesquisa qualitativa seria capaz de captar as nuances desse contexto cibercultural.

Observamos as publicações de um conjunto formado por 10 blogs autodeclarados feministas durante o período de um mês. Antes de tudo, foi criada uma conta pessoal no Tumblr, a rede onde se hospedam os blogs observados, a fim de fazer parte desse espaço e compreender a sua dinâmica. Após a criação, foi feita uma pesquisa na caixa de busca utilizando a palavra "feminismo", sendo selecionados os cem primeiros blogs a aparecer nos resultados.

Mesmo pesquisando por uma palavra em português, muitos dos resultados eram na língua inglesa, que hoje em dia pode ser considerada a língua franca universal. Portanto, foram analisados blogs com postagens tanto em português quanto em inglês, e por vezes, em espanhol. Em seguida, foram excluídos da seleção os blogs desatualizados ou que não publicavam nada há mais de um mês. Foi utilizado o critério de assiduidade, considerando apenas os blogs que possuíam no mínimo vinte publicações por mês, chegando ao número final de dez blogs após essas diversas filtragens.

Após a observação e análise das publicações algumas categorias surgiram dentro de três blocos principais, sendo elas: formato, fonte e tipo de publicação. $\mathrm{O}$ formato dizia respeito ao tipo de mídia utilizado, por exemplo, imagem, texto, vídeo, etc. $\mathrm{Na}$ fonte, buscamos saber de onde vinham as informações, ou seja, onde ou por quem foram produzidas, se em outras redes sociais (através de prints do Twitter ou Instagram), cinema, jornal, ou pelos próprios membros do Tumblr. Já o tipo de postagem se tratou do bloco mais complexo e com mais nuances, em que analisamos o conteúdo das publicações, seus objetivos e vieses, por exemplo, publicações focadas em denúncias, ou que utilizam de humor, ou com viés artístico e assim por diante.

A descrição e análise das categorias mais utilizadas dentro desses três blocos ajudaram a perceber as estratégias de visibilidade mais populares e efetivas dentro da rede, pois eles se interligam entre si, e o conjunto formato, fonte e tipo de publicação constrói a constelação de conteúdos e interações no Tumblr, demonstrando o que mais chama a atenção entre os seus membros.

No Tumblr não é possível saber quais publicações são autorais ou não. Porém, assume-se que ao compartilharem tais conteúdos, os blogs seguidos expõem suas preferências, desejos, gostos, pensamentos e posições políticas. Segundo Sibilia (2008), o objetivo da exposição e espetacularização da vida íntima na web é tornar uma subjetividade visível. Assim, nos blogs analisados são apresentadas visões do que é o feminismo e o que ser feminista. Portanto, mesmo 
que não exponham conteúdos autorais, as pessoas por trás dos blogs se utilizam dos materiais que compartilham para falar de si, do que acreditam, e para serem reconhecidas por meio do que ali expõem.

\section{RESULTADOS E ANÁLISES}

Para apresentar os resultados e desenvolver as análises organizamos o estudo a partir de três categorias: formato, fonte e tipo de publicação.

\section{Formato}

O Tumblr é conhecido por ser uma rede majoritariamente visual, onde a maior parte de seu conteúdo é constituída de imagens, e isso se comprova com os resultados da coleta de dados (Tabela 1), onde $58 \%$ das postagens são imagens ${ }^{4}$, divididas entre fotografias e $\mathrm{GIFs}^{5}$. Seguidas pelo texto que era o formato de $26 \%$ das publicações.

Tabela 1 - Frequência de formatos

\begin{tabular}{|l|l|}
\hline \multicolumn{1}{|c|}{ Formato } & \multicolumn{1}{c|}{ Frequência } \\
\hline Fotografia & $39 \%$ \\
\hline Texto & $26 \%$ \\
\hline GIF & $19 \%$ \\
\hline Vídeo & $8 \%$ \\
\hline Citação & $5 \%$ \\
\hline Resposta & $3 \%$ \\
\hline
\end{tabular}

Fonte: Tabela elaborada pelos autores

Entender a cultura visual no Tumblr é essencial para entender a rede como um todo, assim como o uso de imagens em outras redes, a exemplo do Facebook que, influenciado pelo Tumblr, passou a aceitar GIFs em sua timeline. Segundo Lance Ulanoff (2016), o Tumblr teve um papel fundamental na ressurreição dos GIFs na cultura da internet. A partir do momento em que essa rede passa a ser usada principalmente para se demonstrar o amor ou não amor extremo pelos gostos pessoais e/ou ídolos, e combinando isso ao crescimento de plataformas de vídeos como Youtube e Vimeo, começou-se a publicar massivamente pequenos trechos de vídeos com "o que se gostava".

\footnotetext{
${ }^{4} \mathrm{O}$ número total de postagens para se chegar a essas porcentagens foi de 306.

${ }^{5}$ Sigla para Graphics Interchange Format (Formato para Intercâmbio de Gráficos). GIFs são basicamente uma animação sem áudio e limitada visualmente em loop.
} 
Considerando que no Tumblr podemos ter uma linha do tempo "limpa" e simples, para dar ênfase especial ao visual, ele se tornou mais um local ideal para o compartilhamento dos GIFs.

Como GIFs normalmente não possuem áudios, os usuários passaram a incorporar legendas para que se soubesse o que se falava nos vídeos de onde os trechos foram tirados. Essa intervenção abriu portas para que outras experimentações fossem feitas, principalmente levando-se em consideração que é muito simples para um usuário da internet criar GIFs através de programas como o Photoshop (MIGLIOLI e BARROS, 2013). Os GIFs se tornaram um fenômeno tão grande dentro e fora do site que o blog oficial do Tumblr chegou a brincar dizendo que essas animações substituíram a obsoleta linguagem escrita ${ }^{6}$.

Com o passar do tempo, foram criadas também formas específicas de organização de imagens no Tumblr, através dos gifsets (um conjunto de GIFS) e photosets (um conjunto de fotos), conjuntos de imagens combinadas e diagramadas que compõem um mesmo post: "Através desse recurso, usuários conseguem reproduzir cenas inteiras através de GIFs sequenciais retirados de conteúdo audiovisual e, até mesmo, criar suas próprias narrativas" (AMARAL, 2016, p. 68). Um exemplo de estrutura de gifset pode ser visto na figura 2.

\footnotetext{
6 Disponível em: <https://staff.tumblr.com/post/120720833005/since-gifs-have-replaced-written-language-were> Acesso em 25 abr. 2019.
} 


\section{Figura 2. Gifset. $^{7}$}
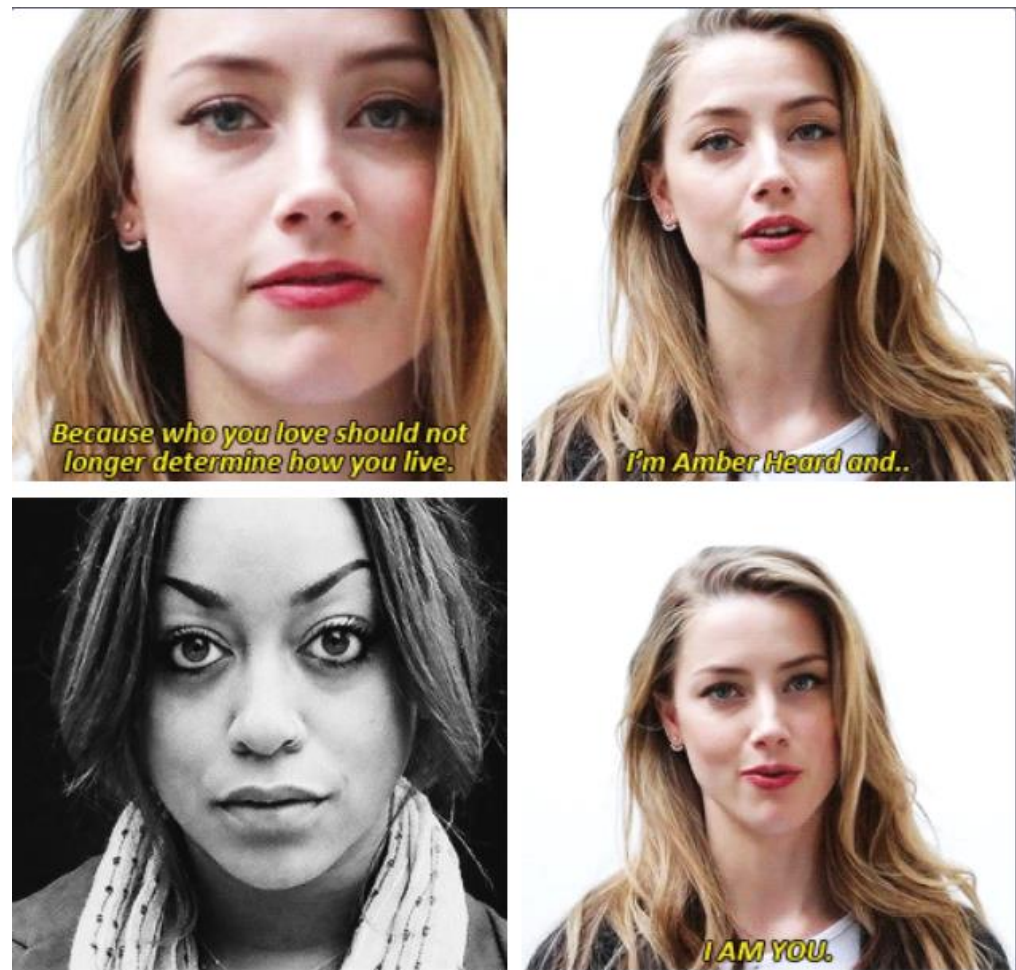

Fonte: Figura elaborada pelos autores a partir de publicações no Tumblr

Passando para o texto, o segundo formato predominante, vale à pena ressaltar que diferentemente de plataformas de microblogging como o Twitter, o Tumblr não tem limites de caracteres, o que proporciona a criação e compartilhamento de textos maiores e com análises mais complexas sobre os mais diversos temas. A partir do momento que se comenta, o conteúdo comentado passa a aparecer em sua página pessoal. Isso gera um fluxo enorme de conteúdo e discussão. Além do mais, os comentários podem ser feitos tanto em formato de texto quanto em imagem, permitindo misturas e formas de expressão do modo com o qual o usuário se sente mais à vontade.

Quanto às demais possibilidades de formato permitidas pelo Tumblr, não notamos um uso significativo. Sendo os formatos mais utilizados e populares os textos, fotos e GIFs.

\section{Fonte}

Percebemos que grande parte do conteúdo publicado possuía como fonte a mídia de massa, como telejornais, grandes portais de notícia, filmes, séries de TV e peças publicitárias. Isso conectase com o fato de que no Tumblr existe uma gama de discussões e conteúdos relacionados à cultura

\footnotetext{
${ }^{7}$ Disponível em: 〈http://lionsdance.tumblr.com/post/145161284093/ambers-heard-we-are-you-amber-heard-supports>. Acesso em 25 mai. 2017.
} 
pop, sendo um local de constante demonstração de amor e admiração pelos ídolos. Quase não há conteúdo produzido de forma amadora como é o caso de redes como Facebook e Twitter.

Notamos também que há uma grande circulação de conteúdos de outras redes sociais como o Twitter e o Instagram. Esse tipo de conteúdo aparece no Tumblr em formato de prints (captura de tela), demonstrando uma interconexão entre essas redes, sendo comum o fluxo de discussões, não se resumindo aos temas fechados de cada rede. A predominância de conteúdo proveniente do Twitter demonstra a influência dessa rede nos debates de alcance global e como ela funciona como uma ágora de discussões e circulação de informação.

Tabela 2. Frequência de fonte

\begin{tabular}{|l|l|}
\hline \multicolumn{1}{|c|}{ Fonte } & \multicolumn{1}{c|}{ Frequência } \\
\hline Mídia & $44 \%$ \\
\hline Twitter & $34 \%$ \\
\hline Pessoal/Amador & $18 \%$ \\
\hline Instagram & $4 \%$ \\
\hline
\end{tabular}

Fonte: Tabela elaborada pelos autores.

Os conteúdos de fonte pessoal eram geralmente vídeos curtos ou pequenos textos de desabafo ou dando conselhos de como se comportar ou pensar de acordo com um "bom feminismo". Eles se enquadravam em um estilo mais confessional, que ocorre bastante no Tumblr, mas não tanto quanto a exposição do que se gosta através do reblog de GIFs e imagens dos ídolos ou de causas com as quais se simpatiza. Outro tipo de conteúdo pessoal comum são as artes visuais ou poemas com mensagens feministas, mas cuja autoria não pode ser localizada, portanto, não se sabe se foram artes criadas pelas pessoas atrás do blog ou por terceiros. De qualquer forma, esse tipo de conteúdo artístico mais pessoal e independente fugia do padrão de imagens e textos advindos da mídia de massa.

\section{Tipos de publicação}

Essa foi a categoria mais complexa, que exigiu mais atenção e sensibilidade para se perceber as nuances de cada publicação, podendo uma só publicação pertencer a mais de uma categoria. Uma das categorias predominantes foi a de cunho informativo. Foram consideradas como tal, matérias de jornal, quadros explicativos, textos ou imagens sobre fatos históricos, curiosidades, infográficos, 
trechos de documentários e qualquer tipo de conteúdo que possuísse como objetivo principal informar seus leitores sobre algo considerado importante ou relevante.

Uma das principais características desse tipo de publicação eram seus longos textos explicativos. A falta de limite de caracteres permite a publicação de textos extensos sobre os mais diversos temas, assim como longas discussões em que cada usuário expõe minuciosamente suas opiniões e pontos de vista em relação a cada postagem. Geralmente esses textos mais longos vêm acompanhados de imagens ilustrativas. A organização de imagem e texto nesse tipo de publicação lembra bastante a estrutura de matérias de jornais online, o que permite que o Tumblr seja utilizado também como uma fonte de informação sobre o que acontece no mundo, e no caso desse grupo de blogs feministas, do que concerne aos direitos ou história das mulheres.

Tabela 3. Tipos de publicação

\begin{tabular}{|l|l|}
\hline \multicolumn{1}{|c|}{ Tipo de publicação } & \multicolumn{1}{c|}{ Frequência } \\
\hline Informativo & $19 \%$ \\
\hline Arte & $15 \%$ \\
\hline Exemplos de mulheres & $13 \%$ \\
\hline Denúncia & $10 \%$ \\
\hline Desabafo & $10 \%$ \\
\hline Humor & $7 \%$ \\
\hline Conselhos & $5 \%$ \\
\hline Campanha virtual & $5 \%$ \\
\hline Protesto & $4 \%$ \\
\hline Autoajuda & $3 \%$ \\
\hline Citação de teórica feminista & $3 \%$ \\
\hline Crítica a empresas & $1 \%$ \\
\hline
\end{tabular}

Fonte: Tabela elaborada pelos autores

A segunda categoria mais frequente foi arte. Consideramos conteúdo de cunho artístico aqueles constituídos de poemas, artes visuais, quadrinhos ou arte de rua, geralmente com mensagens feministas, produzidas autonomamente e compartilhadas pelos membros. Um exemplo desse tipo de publicação de cunho artístico e com mensagens feministas pode ser visto na imagem abaixo. 
Figura 3. Stand up for your rights.

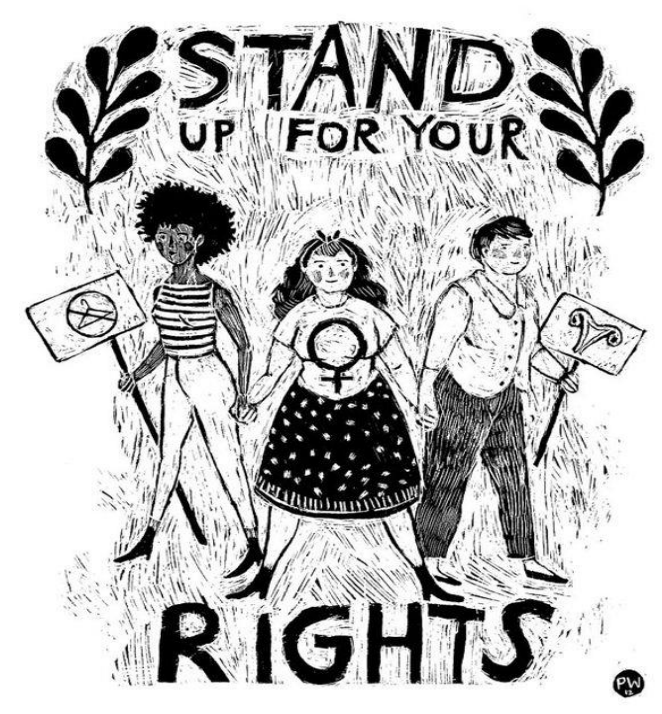

Fonte: Figura elaborada pelos autores a partir de publicações no Tumblr.

$\mathrm{Na}$ imagem, cuja tradução é "lute por seus direitos", vemos três mulheres com placas relativas aos direitos reprodutivos femininos. Esse é um exemplo de publicação que se enquadra na categoria de arte pois, geralmente, incluem desenhos feitos por artistas independentes com mensagens de apoio às causas feministas. E sendo o Tumblr uma rede que incentiva a criatividade e a veia artística dos seus membros era de se esperar esse tipo de conteúdo com apelo visual.

As publicações dessa categoria frequentemente possuíam mensagens positivas ou frases de impacto que visavam reafirmar o status de feminista de quem as compartilhava. Também era comum se representar diferentes biotipos, etnias, raças, em suma, a diversidade das mulheres através dos desenhos. Um dos exemplos está na imagem a seguir, em que se vê uma mulher deficiente, uma mãe, uma muçulmana, uma butch, uma cadeirante e assim por diante. A mensagem escrita diz "forte pra caramba", e todas as mulheres unidas formam um coração. Esse é o tipo de positividade presente nas artes feministas compartilhadas no Tumblr. 
Figura 4. Strong as hell

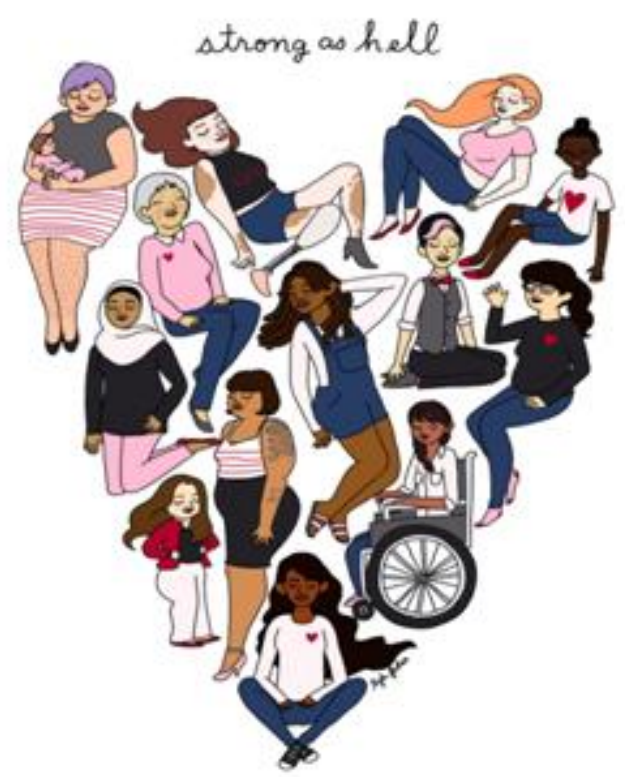

Fonte: Figura elaborada pelos autores a partir de publicações no Tumblr.

Essa preocupação em se mostrar a diversidade das mulheres se relaciona com o terceiro tipo de publicação mais frequente, que diz respeito ao uso de mulheres ilustres ou fora do padrão hegemônico de feminilidade, como forma de inspiração. Geralmente são publicadas fotos de mulheres negras, gordas ou deficientes para que se vejam corpos e fenótipos fora do padrão frequentemente exposto na mídia de massa. Também eram frequentes os exemplos de mulheres que de certa forma auxiliaram no progresso da ciência, ou mulheres notáveis na história e na sua área de atuação.

Segundo Kellner (2001), “o rádio, a televisão, o cinema e os outros produtos da indústria cultural fornecem os modelos daquilo que significa ser homem ou mulher, bem-sucedido ou fracassado, poderoso ou impotente". Esse tipo de representação também altera a percepção das mulheres sobre elas mesmas fazendo com que nunca se vejam de forma humanizada ao serem constantemente sexualizadas nos produtos midiáticos.

O que aprendemos através de artefatos culturais como a mídia de massa é chamado de pedagogias culturais (COSTA; ANDRADE, 2015). Uma das questões centrais dessas pedagogias é a representação dos sujeitos na mídia e como ela ensina modos de pensar e agir. No caso das mulheres, suas representações hegemônicas as fazem se preocupar mais com a aparência do que com o intelecto, com serem líderes ou influentes politicamente. Daí vem a importância de haver 
boas representações na mídia e de conteúdo produzido por mulheres e para mulheres, indo de encontro à hegemonia masculina que, geralmente, controla os produtos midiáticos.

Mostrar mulheres com corpos e fenótipos mais próximos aos da maioria e com as quais é possível haver uma maior identificação faz parte do que os membros do Tumblr chamam de representatividade, e que se faz importante como uma alternativa ao que a mídia costuma ignorar. Dessa forma, se enxergar em artefatos culturais é importante para a construção da autoestima e para a autoaceitação, o que é essencial para uma boa saúde mental. Além disso, o compartilhamento de informação sobre mulheres importantes na história auxilia no incentivo das jovens a seguirem seus próprios caminhos, a fim de tentarem feitos importantes espelhadas nessas mulheres ilustres e/ou admiráveis.

Nesse ponto percebemos uma aparente contradição. A maior parte do conteúdo publicado no Tumblr vem da mídia de massa, influenciado pela cultura pop, porém, ao mesmo tempo, os membros do Tumblr aparentam possuir um certo senso crítico em relação a essa mídia hegemônica. Conjuntamente ao consumo desses produtos culturais, se exige mais representatividade e também se critica e se denuncia o que vai de encontro aos seus ideais enquanto pessoas autodeclaradas feministas.

Nota-se, então, uma similaridade das pedagogias culturais com os pressupostos da pedagogia crítica. Henry Giroux (2008), ao analisar artefatos midiáticos tais como filmes de Hollywood e desenhos da Disney, destaca que eles, ao mesmo tempo que reafirmam estereótipos de gênero e raça dão condições para que, por intermédio de uma pedagogia crítica, essas narrativas sejam reescritas através do desenvolvimento de mecanismos de resistência contra os discursos hegemônicos.

A pedagogia crítica atenta à produtividade dos artefatos da cultura e os investiga para denunciar as formas de ideologia e dominação presentes nos discursos e representações que produzem. O que vemos é uma pedagogia politicamente engajada, que atrela fortemente o papel do educador ao processo de mudar sua realidade sóciocultural (ANDRADE, 2015, p. 5).

Essa pedagogia engajada ressalta a importância de se romper silenciamentos e promover a denúncia. Era muito comum se denunciar artistas ou programas de TV com atitudes machistas, racistas ou consideradas opressoras de alguma maneira. Como em um texto que denuncia Johnny Depp após acusações de violência doméstica do ator para com a sua esposa. Aparentemente a grande mídia estava ignorando o caso e os membros do Tumblr publicaram inúmeros posts o denunciando e demonstrando apoio a sua ex-companheira. 
Outro exemplo é o gifset de uma apresentadora da previsão do tempo de um telejornal sendo obrigada a usar um casaco durante sua fala. As ativistas feministas enviaram diversos e-mails na condição de telespectadoras incomodadas com o vestido que ela usava. Essa publicação incluía tweets indignados com a postura do jornal diante da situação e link para uma matéria sobre o caso. Isso mostra a integração do Tumblr com o Twitter e os grandes canais de comunicação, assim como um engajamento com o que ocorre na mídia, e no caso da comunidade feminista no Tumblr, o que ocorre com mulheres na mídia.

Porém, apesar desses tipos de publicação aparentarem ser bastante sérios, o Tumblr é conhecido também pelo seu humor, como por exemplo na imagem a seguir que denuncia a hipersexualização de mulheres nos games, ao mesmo tempo que utiliza de humor.

Figura 5. Uso de humor. ${ }^{8}$

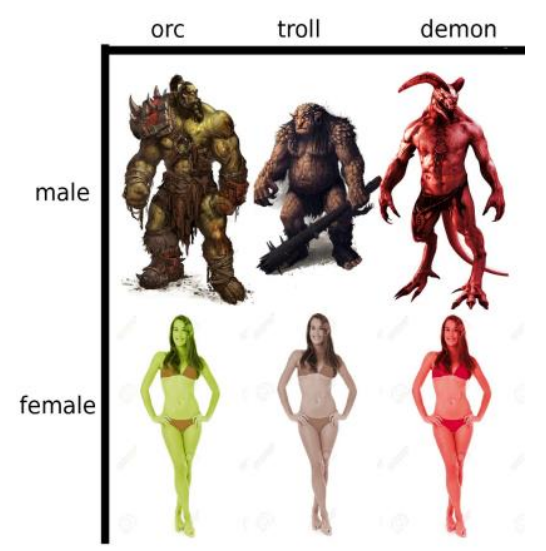

Fonte: Figura elaborada pelos autores a partir de publicações no Tumblr.

Branagan (2007) revela em seu estudo sobre humor e ativismo que o humor é altamente inclusivo e pode ser utilizado para convencer pessoas a apoiar argumentos específicos, para comunicar algo ou para chegar a mais pessoas. Ao rir de uma piada se mostra uma aceitação e entendimento de uma determinada cultura ou simbologia. Quando se ri de uma piada de cunho feminista compreende-se um entendimento desse movimento político, muitas vezes em relação a tópicos profundos e difíceis.

No caso dessa imagem, demonstra-se um entendimento sobre a hiperssexualização de personagens femininas nos jogos. Mesmo sendo criaturas mágicas essas figuras femininas serão

\footnotetext{
${ }^{8}$ Disponível em: <http://radical-feminsim.tumblr.com/post/144546475202/susiethemoderator-fragilefontaine-rottikins\# notes $>$. Acesso em 26 abr. 2017.
} 
sexualizadas de uma forma diferente da dos masculinos, que são comumente mais complexos e diversos. Até personagens que deveriam ser assustadoras, como no caso de trolls, orcs e demônios, se tornam sensuais e são vestidas de forma insinuante. Ao se perceber a graça dessa imagem, obviamente exagerada, os usuários do Tumblr demonstram entender tanto da cultura dos videogames quanto possuir uma visão crítica da representação de figuras femininas nesses jogos, colocando em prática uma pedagogia crítica da mídia. Além do mais, essa grande quantidade de publicações humorísticas rompe com o senso comum de que feministas não tem senso de humor.

\section{CONSIDERAÇÕES FINA}

A análise dos conteúdos postados nos blogs nos levam a diversas conclusões, das quais destacamos três.

Primeiro, observamos que no Tumblr são fornecidas narrativas e representações alternativas ao padrão hegemônico disseminado na mídia de massa do que é ser mulher, assim como também se questiona e se exige uma melhor representação da mulher e de minorias na mídia de massa, colocando-se em prática uma pedagogia crítica com viés feminista.

Em segundo, os participantes do Tumblr ao mesmo tempo que aprendem, disseminam conhecimento sobre a situação da mulher na contemporaneidade e da importância do feminismo para uma igualdade entre os sexos. Isso gera uma pedagogia de compartilhamento tanto para o autoaprendizado quanto para educar aos demais, assim como incentiva a criatividade e a criação de conteúdo, seja artístico ou humorístico, aprendendo e ensinando sobre feminismo através dos mais diversos vieses.

A terceira e última conclusão é que a visibilidade na rede não é apenas para o eu, mas também para uma causa. A busca pela visibilidade é uma estratégia também ativista. Se utiliza dessas narrativas para visibilizar causas maiores e também para educar. Não se trata de um processo narcisista cujo foco é apenas o eu, mas da defesa de uma causa social. Isso demonstra que não se está sozinho e que existem muitas outras pessoas que enxergam as injustiças do mundo de forma crítica, e essa mudança no pensamento é o primeiro passo para mudanças mais profundas na sociedade. 


\section{REFERÊNCIAS}

AMARAL, L. L. As apropriações do GIF animado: Aspectos culturais, expressivos e afetivos dos usos de uma tecnologia defasada. Porto Alegre, RS. Dissertação de mestrado. Universidade Federal do Rio Grande do Sul, 2016, 279 p. Disponível em https://lume.ufrgs.br/handle/10183/142516. Acesso em 12 jun. 2019.

ANDRADE, P. D. Pedagogias culturais: as condições teóricas que possibilitaram a emergência do conceito. In: $6^{\circ}$ Seminário Brasileiro de Estudos Culturais/ $3^{\circ}$ Seminário Internacional de Estudos Culturais - Educação, Transgressões e Narcisismos, 2015, Canoas. Anais Eletrônicos Bianual, v. 1. p. 1-12.

BRANAGAN, M. Activism and the Power Of Humor. Australian Journal of Communication 34(1), 2007, 41-54.

CASTELlS, M. A sociedade em rede. Tradução de Roneide Venâncio Majer. São Paulo: Editora Paz e Terra, 8ed. 2005.

CHANG, Y. et al. What is Tumblr: A Statistical Overview and Comparison. SIGKDD Explorations, Vol. $16(1), 2014$. Disponível em: <http://yichangcs.com/yahoo/KDDExp14_Tumblr.pdf>. Acesso em: 22 mar. 2019.

COSTA, M. V.; ANDRADE, P. D. Na produtiva confluência entre educação e comunicação, as pedagogias culturais contemporâneas. Perspectiva (UFSC), v. 33, 2015, p. 843-862. Disponível em https://periodicos.ufsc.br/index.php/perspectiva/article/view/2175-795X.2015v33n2p843. Acesso em 10 jun. 2019.

COUTO, E. S. Educação e redes sociais digitais: privacidade, intimidade inventada e incitação à visibilidade. Revista Em Aberto, Brasília, v. 28, n. 94, jul./dez, p. 51-61. Disponível em http://emaberto.inep.gov.br/ index.php/ emaberto/article/view/1668. Acesos em 11 jun. 2019.

FRAGOSO, S. et a.. Métodos de pesquisa para internet. Porto Alegre, Sulina, 2011.

GIROUX, H. Memória e Pedagogia no maravilhoso Mundo da Disney. In: SILVA, T. (Org.). Alienígenas na sala de aula: uma introdução aos estudos culturais em educação. 7. ed. Petrópolis, RJ: Vozes, 2008, p. 132-158

KELLNER, D. A cultura da mídia - estudos culturais: identidade e política entre o moderno e o pós-moderno. Trad. Ivone Castilho Benedett. Bauru, SP: EDUSC, 2001.

LASTA, E; BARRICHELlO, E. Proposta de uma matriz de análise de estratégias sociotécnicas de visibilidade e legitimidade presentes em blogs corporativos. In: Intercom - RBCC. São Paulo, v.36, n.1, 2013, p. 249-268, jan./jun. Disponível em: 〈http://www.scielo.br/pdf/interc/v36n1/13.pdf〉 . Acesso em: 21 mar. 2019.

LÉVY, P. Cibercultura. Tradução de Carlos Irineu da Costa. São Paulo: Editora 34, 1999.

MALINI, F.; ANTOUN, H. A internet e a rua: ciberativismo e mobilização nas redes sociais. Porto Alegre: Sulina, 2013.

MIGLIOLI, S.; BARROS, M. Novas tecnologias da imagem e da visualidade: GIF animado como videoarte. Sessões do Imaginário, v. 18, 2013, p. 68-75.

RECUERO, R. Redes sociais na internet. Porto Alegre: Sulina, 2009.

SAFronoVA, V. Millennials and the Age of Tumblr Activism. The New York Times, New York, 19 dez. 2014. Disponível em: <http://www.nytimes.com/2014/12/21/style/millennials-and-the-age-of-tumblr-activism.html?_r=0 > Acesso em: 23 mar. 2019.

SANTAELLA, L.; LEMOS, R. Redes sociais digitais: a cognição conectiva do Twitter. São Paulo: Paulus, 2010.

SANTANA, C.; COUTO, E. S. Estratégias de visibilidade e ações docentes no Twitter. Revista Educação (UFSM), v. 42, n. 2, maio/ago. 2017. Disponível em: https://periodicos.ufsm.br/reveducacao/article/view/22553. Acesso em: 20 mar. 2019.

SIBILIA, P. O show do eu: A intimidade como espetáculo. Rio de Janeiro, Nova Fronteira, 2008.

ULANOFF, L. The secret history of the GIF. 2016. Disponível em: <http://mashable.com/2016/08/10/history-of-thegif/\#Tg3cwyFraOqw>. Acesso em 25 jan. 2019.

SIllEIRA, S. A; BRAGA, S.; PENTEADO, C. (Org.) Cultura, política e ativismo nas redes digitais. São Paulo: Fundação Perseu Abramo, 2014. 


\section{RESUMO}

O objetivo do artigo é identificar, descrever e analisar o ativismo e as estratégias de visibilidade utilizadas por um grupo de blogs do site de rede social Tumblr autodeclarados feministas. $O$ artigo foca nas estratégias de visibilidade utilizadas por esses blogs, considerando essa uma rede social jovem e com constante circulação de conteúdo feminista. Utilizamos como base teórica os estudos sobre Redes Sociais na Internet e cibercultura e pressupostos da Pedagogia Crítica. O método foi o qualitativo, de cunho descritivo e analítico. Os resultados mostram que os membros do Tumblr, ao mesmo tempo que consomem os produtos da mídia de massa, também produzem críticas e denúncias através de um viés feminista que preza pela melhor representação da mulher nesses espaços.

Palavras-chave: Ativismo, visibilidade, feminismo.

\section{ACTIVISM AND VISIBILITY STRATEGIES OF FEMINIST BLOGS ON TUMBLR}

\section{ABSTRACT}

This article aims to identify, describe and analyse the activism and visibility strategies used by a group of self identified feminist blogs on Tumblr. The article focuses on the visibility strategies used by those blogs, considering them a young social network with a massive amount and circulation of feminist content. The theoretical framework consisted of Social Networks and Cyberculture studies, as well as Critical Pedagogy. The method was qualitative, descriptive and analytical. The results show that Tumblr members consume mass media products and, at the same time, criticize them through a feminist point of view fighting for a better representation of women in these spaces.

Keywords: Activism, visibility, feminism.

\section{ACTIVISMO Y ESTRATEGIAS DE VISIBILIDAD DE BLOGS FEMINISTAS EN EL TUMBLR}

\section{RESUMEN}

El objetivo del artículo fue identificar, describir y analizar el activismo y las estrategias de visibilidad utilizadas por un grupo de blogs autodeclarados feministas de la plataforma de red social Tumblr. El artículo se centra en las estrategias de visibilidad utilizadas por esos blogs, al considerarse a la red social de esa plataforma de tipo joven y con constante circulación de contenido feminista. Utilizamos como base teórica estudios sobre Redes Sociales en Internet y cibercultura y principios de Pedagogía Crítica. El método es de tipo cualitativo, de carácter descriptivo y analítico. Los resultados muestran que los miembros de Tumblr, al tiempo que consumen productos de los medios de comunicación, también producen críticas y denuncias con sesgo feminista que se aprecia mediante una mejor representación de la mujer en esos espacios.

Palabras clave: Activismo, visibilidad, feminismo. 